\section{Being FDA commissioner is a tough job, requiring equal parts consummate manager, technocrat and Lord High Executioner.}

\title{
FDA HEAD WANTED, WIMPS NEED NOT APPLY
}

The departure of FDA Commissioner Mark McClellan in March 2004 has created a high-level opening in the Bush administration for the right candidate. It's a tough job, but a potentially rewarding one, offering the opportunity to influence policies and decisions that affect the profitability of products worth more than a trillion dollars annually.

Those with an independent streak or industrial experience need not apply. The Bush administration will require that the new commissioner toe the party line on reproductive issues, therapeutic cloning and reimportation of drugs to the United States from countries such as Canada. Senator Ted Kennedy (D-Massachusetts), the most senior minority member of the Senate Health, Education, Labor and Pensions Committee (which must confirm the nominee put forth by the president), will reject any candidate with past ties of any kind to regulated industry. If Senator John Kerry were elected as president, he would undoubtedly nominate a more regulation-minded, less reform-inclined person for commissioner, but Senator Kennedy's views about prior industry experience would still hold sway.

Ideally, the nominee for FDA commissioner should be equal parts consummate manager, technocrat and Lord High Executioner. Realistically, he or she must have the following attributes.

Superior management skills and experience. The agency's scope is so sweeping - encompassing cardiac pacemakers, $\mathrm{X}$-ray machines, condoms, home pregnancy-testing kits, drugs, vaccines, artificial sweeteners and fat substitutes that a single person cannot be expected to master the body of science, medicine, pharmacology and engineering (to say nothing of the law and 'regulatory science') involved. The FDA's own professional staff frames the issues and options; the function of the agency head is chiefly to manage the far-flung empire, to craft appropriate incentives for moving products through the pipeline more efficiently, and to make the final decision on difficult policy questions.

Unassailable integrity and honesty. The commissioner's decision-making must meld law, science, medicine and regulatory precedents in a way that maximizes public interest. The incumbent needs to earn the respect of those who have a stake in FDA's policies and decisions - that is, patient groups, individual consumers and drug companies - with candour, consistency and rectitude.

Commitment to regulatory reform. The FDA needs to streamline its existing regulatory procedures, eliminate unnecessary requirements and work with Congress on new approaches that offer non-governmental alternatives to some of the agency's functions. The latter could include enhanced reliance on extramural expert advisory committees, contracting out product reviews, and the creation of extra-governmental oversight mechanisms.

For example, the regulation of medical devices in the European Union (EU) relies heavily on various sets of product standards and normally does not involve government regulators directly in product oversight. For lowrisk devices, manufacturers themselves are allowed to certify that their products meet the necessary standards. For higher-risk products, manufacturers must obtain third-party review from private-sector, profit-making entities - 'notified bodies' - that test products, inspect manufacturing systems, and ultimately verify that EU standards have been met. Another apposite model, in the United States, is the Nationally Recognized Testing Laboratories. The prototype of this is Underwriters Laboratories, a private, non-profit entity that crafts standards for and certifies compliance with them for tens of thousands of categories of consumer products, ranging from lighting fixtures and flame-retardant chemicals to bullet-resistant glass.

In addition, the FDA's senior and mid-level managers must be made more accountable for their decisions especially those that delay the availability of new drugs, vaccines and medical devices to patients in need of them. One way to achieve this aim is to create an independent, strong ombudsman mechanism that could impose negative sanctions on civil servants who transgress. This is where the role of Lord High Executioner comes in: the agency head cannot make a public policy omelette without breaking some bureaucratic eggs. Putting it another way, some of the FDA's senior managers consistently fail to hold their subordinates accountable for scientifically insupportable policies and decisions that needlessly delay the availability of life-saving products. All but a handful of the agency's 9,000 employees are career civil servants and, therefore, cannot be sacked, but senior managers can easily be moved to other positions.

Distanced from politics. The FDA commissioner's job should not be awarded as a political plum, as are cabinet posts and many ambassadorships. Politics should be banished as much as possible, with the commissioner doing what is in the public interest first, and then taking the heat from all quarters for unpopular decisions. Under Commissioner McClellan, not only broad policies but also some decisions on individual products - such as the decision not to approve the 'Plan B' morning-after contraceptive for over-the-counter use - seemed to be dictated by political considerations. A corollary is that the commissioner should probably not aspire to higher political positions in government: doing the job right makes plenty of enemies.

Applications may be sent to The White House, 1600 Pennsylvania Avenue NW, Washington DC 20500, USA. 